\title{
Radiolysis of astrophysical ices by heavy ion irradiation: destruction cross section measurement
}

\author{
A.L.F. de Barros ${ }^{1}$, P. Boduch ${ }^{2}$, A. Domaracka ${ }^{2}$, H. Rothard ${ }^{2}$, and E.F. da Silveira ${ }^{3}$ \\ ${ }^{1}$ Departamento de Disciplinas Básicas e Gerais, CEFET-RJ, Av. Maracanã 229, 20271-110 Rio de Janeiro, RJ, Brazil \\ E-mail: ana1barros@gmail.com \\ ${ }^{2}$ Centre de Recherche sur les Ions, les Matériaux et la Photonique (CEA/CNRS/ ENSICAEN/Université de Caen-Basse \\ Normandie), CIMAP-CIRIL-Ganil, Boulevard Henri Becquerel, BP 5133, F-14070 Caen Cedex 05, France \\ E-mail: rothard@ganil.fr \\ ${ }^{3}$ Departamento de Física, Pontifícia Universidade Católica do Rio de Janeiro, Rua Marquês de São Vicente 225, \\ 22451-900, Rio de Janeiro, RJ, Brazil
}

Received April 19, 2012

\begin{abstract}
Many solar system objects, such as planets and their satellites, dust grains in rings, and comets, are known to either be made of ices or to have icy surfaces. These ices are exposed to ionizing radiation including $\mathrm{keV}, \mathrm{MeV}$ and $\mathrm{GeV}$ ions from solar wind or cosmic rays. Moreover, icy dust grains are present in interstellar space and in particular in dense molecular clouds. Radiation effects include radiolysis (the destruction of molecules leading to formation of radicals), the formation of new molecules following radiolysis, the desorption or sputtering of atoms or molecules from the surface, compaction of porous ices, and phase changes. This review discusses the application of infrared spectroscopy FTIR to study the evolution of the chemical composition of ices containing the most abundant molecular species found in the solar system and interstellar medium, such as $\mathrm{H}_{2} \mathrm{O}, \mathrm{CO}, \mathrm{CO}_{2}$ and hydrocarbons. We focus on the evolution of chemical composition with ion fluence in order to deduce the corresponding destruction and formation cross sections. Although initial approach focused on product identification, it became increasingly necessary to work toward a comprehensive understanding of ice chemistry. The abundances of these molecules in different phases of ice mantles provide important clues to the chemical processes in dense interstellar clouds, and therefore it is of importance to accurately measure the quantities such as dissociation and formation cross sections of the infrared features of these molecules. We also are able to obtain the scaling of these cross sections with deposited energy.

PACS: 34.50.-s Scattering of atoms and molecules;

61.80. $-\mathbf{x}$ Physical radiation effects, radiation damage;

33.20.Ea Infrared spectra;

82.30.Fi Ion-molecule, ion-ion, and charge-transfer reactions.
\end{abstract}

Keywords: ion irradiation, astrophysical ices, destruction cross sections.

\section{Introduction}

Most of the outer space is at temperatures in the order of 10 to $80 \mathrm{~K}$. In these regions, and at these temperatures, gases formed by relatively simple molecules such as nitrogen $\left(\mathrm{N}_{2}\right)$, oxygen $\left(\mathrm{O}_{2}\right)$, water $\left(\mathrm{H}_{2} \mathrm{O}\right)$, carbon monoxide (CO), carbon dioxide $\left(\mathrm{CO}_{2}\right)$, ammonia $\left(\mathrm{NH}_{3}\right)$ and methane $\left(\mathrm{CH}_{4}\right)$ condense to form ice, which can be observed in comets, on the surface of satellites of giant planets and in interstellar grain mantles. In space, the ices are exposed to ion irradiation (stellar winds and galactic cosmic rays) ranging from protons up to heavy ions such as Fe, with kinetic energies from $\mathrm{keV}$ to $\mathrm{TeV}$. Such bombardment leads to fragmentation of molecules inside the ice samples, as well as sputtering and formation of new molecules. Infrared astronomy has led to the identification of various species existing within icy grain mantles in dense clouds. The two most abundant molecules in grain mantles identified to date are $\mathrm{H}_{2} \mathrm{O}$ and $\mathrm{CO}$ (e.g., [1-5]). Limited observational evidence as well as theoretical and laboratory modeling indicate that carbon dioxide $\left(\mathrm{CO}_{2}\right)$ should also be an important component of interstellar ices [2,6]. The goal of 
this paper is to describe briefly some of the experiments performed at GANIL (Grand Accelerateur National d'Ions Lourds, Caen, France). As part of a systematical study on effects induced by heavy ions, our collaboration has previously reported results on pure $\mathrm{H}_{2} \mathrm{O}, \mathrm{CO}, \mathrm{CO}_{2}, \mathrm{HCOOH}$, $\mathrm{NH}_{3}, \mathrm{CH}_{3} \mathrm{OH}$ and $\mathrm{CH}_{4}$ ices. Also, water mixtures such as: $\mathrm{H}_{2} \mathrm{O}: \mathrm{CO}_{2}, \mathrm{H}_{2} \mathrm{O}: \mathrm{CO}, \mathrm{H}_{2} \mathrm{O}: \mathrm{NH}_{3}, \mathrm{H}_{2} \mathrm{O}: \mathrm{H}_{2} \mathrm{CO}$ and $\mathrm{H}_{2} \mathrm{O}: \mathrm{NH}_{3}: \mathrm{CO}$ ices were irradiated with $\mathrm{MeV}$ ions and $\mathrm{CO}, \mathrm{CO}_{2}$ with $\mathrm{keV}$ ions. In this work, only the dissociation cross-section results obtained for $\mathrm{keV}$ and $\mathrm{MeV}$ projectile energies are presented.

\section{Experimental method}

In a typical "cosmic-ice" radiation experiment, a sample consisting of the molecules of interest is prepared by condensation of a room-temperature vapor onto a pre-cooled substrate in a vacuum chamber. The substrate temperature is usually selected with the temperature of a specific astronomical environment in mind. In this section the experimental setup and procedures used for producing and analyzing astrophysical ice analogs are described.

\subsection{Sample chamber}

The vacuum system used to analyze the ice samples adequate for infrared transmission analysis has been described previously [7-9]. The infrared transmitting substrate (CsI) is mounted in the vacuum chamber and can be cooled down by a closed-cycle helium refrigerator to a temperature of $\sim 14 \mathrm{~K}$. Typical residual gas pressure was $2 \cdot 10^{-8}$ mbar. For each deposition system, the gas flow from a storage tank to the vacuum system was regulated by a variable leak valve. The sample-cryostat system can be rotated by $180^{\circ}$ and fixed at three different positions to allow i) gas deposition, ii) FTIR measurement, and iii) perpendicular ion irradiation, as described in Fig. 1. The homogeneity of the ice samples produced with the deposition tubes was checked by varying the spot size of the infrared beam on the sample using the variable aperture in front of the infrared source of the spectrometer. Samples were found to be homogeneous within $10 \%$ inside a diameter of $1.2 \mathrm{~cm}$.

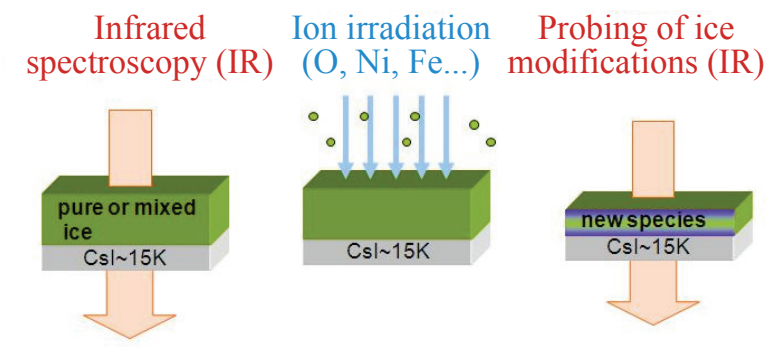

Fig. 1. Schematic diagram of the experimental procedure. The ion beam impinges perpendicularly on the thin ice film deposited on a CsI crystal.

\subsection{FTIR analysis}

The FTIR chamber was used at different GANIL beam lines: $\operatorname{SME}(\approx 10 \mathrm{MeV} / \mathrm{u}), \operatorname{IRRSUD}(\approx 0.8 \mathrm{MeV} / \mathrm{u})$ and ARIBE $(\approx 1.6 \mathrm{keV} / \mathrm{u})$. In situ analysis was performed by the Nicolet Fourier transform infrared spectrometer (FTIR) spectrometer (Magna 550) to obtain the spectrum in the $5000-600 \mathrm{~cm}^{-1}$ range with spectral resolution of $1 \mathrm{~cm}^{-1}$. The molecular column density of a sample was determined from the relation between optical depth $=\ln \left(I_{0} / I\right)$ and the band strength, $A(\mathrm{~cm} / \mathrm{mol})$, of the respective sample vibration mode [6]. In this expression, $I_{0}$ and $I$ are the intensity of light at a specific frequency before and after passing through a sample, respectively.

The Lambert-Beer equation was used for each spectrum on an optical depth scale by the relation for a different absorption $I(v)=I_{0}(v) \exp (-\varepsilon(v) N)$, in which $I(v)$ is the intensity of the IR beam after and $I_{0}(v)$ the before absorption at wavenumber $v$. The $\varepsilon(v)$ is the wavenumber dependent absorption coefficient (in $\mathrm{cm}^{2}$ ), and $N$ is the column density (molecules per $\mathrm{cm}^{2}$ ).

The absorption relation can also be expressed as a function of the absorbance:

$$
A^{\prime}(v) \equiv \log \frac{I_{0}(v)}{I(v)}=\frac{\varepsilon(v) N}{\ln 10} .
$$

For normal IR incidence, integration of $A^{\prime}(v)$ over the band width $v_{f}-v_{i}$ gives

$$
N=\ln 10 \frac{\int_{v_{i}}^{v_{f}} A^{\prime}(v) d v}{A},
$$

where $A$ is the integral absorption coefficient (in centimeter per molecule), referred here as " $A$-value".

\section{Selected results}

We first consider frozen water, hydrocarbons, and then carbon oxides, all important constituents of solar system and interstellar ices. In each case, typical radiation chemical alterations are described, i.e., giving quantitatively the cross sections obtained for each one.

\section{1. $\mathrm{H}_{2} \mathrm{O}$ and hydrocarbon experiments}

Water is the dominant ice molecule in many astronomical environments, and so it is important to treat its radiation chemistry. On encountering either a high-energy ion or an energetic secondary electron, water molecules will be either ionized or electronically excited. These events give rise to a set of primary products that include charged species, radicals, and closed-shell molecules. Figure 2 shows FTIR spectra of water before and after irradiation. As we can see, under ion irradiation of the amorphous ice, the spectrum scarcely changes, except for a band that appears 


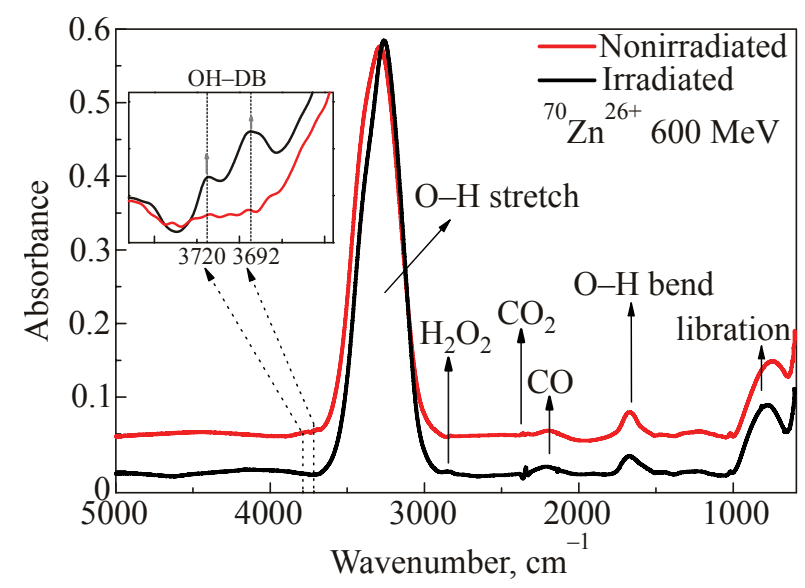

Fig. 2. Infrared spectra of condensed water at $13 \mathrm{~K}$ (amorphous ice) before and after irradiation with $600 \mathrm{MeV} \mathrm{Zn}{ }^{26+}$ beam.

near $2850 \mathrm{~cm}^{-1}$, the other features are water bands or due to some $\mathrm{CO}$ and $\mathrm{CO}_{2}$ contamination. Figure 2 shows an enlargement of the relevant region, before (fluence zero) and after irradiation (high fluence). The band near $2850 \mathrm{~cm}^{-1}$ is due to $\mathrm{H}_{2} \mathrm{O}_{2}$ molecules [10], which we have confirmed by comparison with frozen $\mathrm{H}_{2} \mathrm{O}_{2}$ solutions. Although $\mathrm{H}_{2} \mathrm{O}_{2}$ has been a known radiolysis product of liquid $\mathrm{H}_{2} \mathrm{O}$ for almost a century [11], the spectrum obtained after irradiation in Fig. 2 constitutes its first in situ observation of irradiated $\mathrm{H}_{2} \mathrm{O}$ ice with $600 \mathrm{MeV} \mathrm{Zn}{ }^{26+}$ beam. The accepted mode of $\mathrm{H}_{2} \mathrm{O}_{2}$ formation is combination of $\mathrm{OH}$ radicals, also observed by Moore et al. [12] and Boduch et al. [13]:

$$
\mathrm{OH}+\mathrm{OH}=\mathrm{H}_{2} \mathrm{O}_{2} \text {. }
$$

Our work on $\mathrm{H}_{2} \mathrm{O}$ was motivated by the detection of a $2860 \mathrm{~cm}^{-1}$ feature on Europa's icy surface [14], in which $\mathrm{H}_{2} \mathrm{O}_{2}$ was assigned. Jovian magnetospheric radiation striking Europa dissociates $\mathrm{H}_{2} \mathrm{O}$ ice into $\mathrm{H}$ and $\mathrm{OH}$, and the above $\mathrm{OH}-\mathrm{OH}$ reaction will follow. Another example of the formation of a radical, and its subsequent reaction, is provided by $\mathrm{CH}_{4}$, methane. Irradiated $\mathrm{CH}_{4}$ ice has been studied by several groups $[15,16]$ and is of interest because it is constituent of both a solar system and an interstellar ices. Figure 3 shows IR spectra of $\mathrm{CH}_{4}$ ice before and after irradiation at $16 \mathrm{~K}$. Radiolysis leads the formation of the methyl radical, $\mathrm{CH}_{3}$, which is indicated in Fig. 3, $a$ with an arrow. For example, the combination of methyl radicals by

$$
\mathrm{CH}_{3}+\mathrm{CH}_{3}=\mathrm{C}_{2} \mathrm{H}_{6}
$$

gives $\mathrm{C}_{2} \mathrm{H}_{6}$, ethane, which can be identified in the Fig. 3 from many peaks for the irradiation by $220 \mathrm{MeV}{ }^{16} \mathrm{O}^{7+}$ beam. The remaining features are due to other hydrocarbon products and can be identified by reference spectra of various alkanes, alkenes, and alkynes. These examples involving $\mathrm{H}_{2} \mathrm{O}$ and $\mathrm{CH}_{4}$ were part of efforts to understand the radiation chemistry of saturated and unsaturated hydrocarbons in $\mathrm{H}_{2} \mathrm{O}$ ice. An important aspect of this work is the investigation of $\mathrm{H}$ atom and $\mathrm{OH}$ radical addition reactions

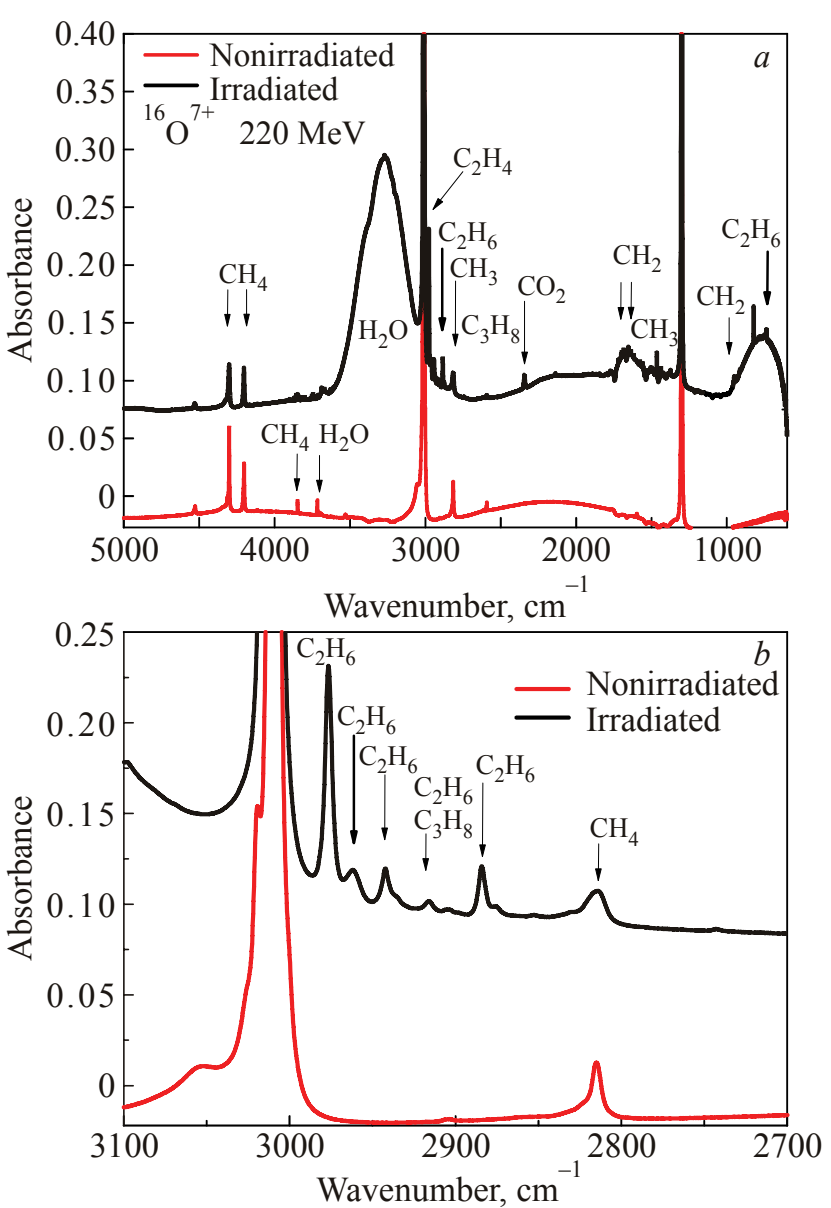

Fig. 3. Comparison of FTIR spectra regions of the $\mathrm{CH}_{4}$ ice at $15 \mathrm{~K}$ before (lower) and after (upper) $220 \mathrm{MeV}$ oxygen ion beam irradiation [18]. The spectrum corresponds to a final fluence of $4.29 \cdot 10^{13}$ ions $/ \mathrm{cm}^{2}$ : ranges of $600-5000 \mathrm{~cm}^{-1}(a)$ and $2700-3100 \mathrm{~cm}^{-1}(b)$.

to carbon-carbon double and triple bonds. Specifically, the discovery of abundant $\mathrm{C}_{2} \mathrm{H}_{6}$ in comet $\mathrm{C} / 1996 \mathrm{~B} 2$ Hyakutake by Mumma et al. [17] led them to suggest $\mathrm{H}$ atom addition to $\mathrm{C}_{2} \mathrm{H}_{2}$, acetylene, as a source of $\mathrm{C}_{2} \mathrm{H}_{6}$. We have confirmed that the sequence [18]:

$$
\mathrm{C}_{2} \mathrm{H}_{2} \rightarrow \mathrm{C}_{2} \mathrm{H}_{4} \rightarrow \mathrm{C}_{2} \mathrm{H}_{6}
$$

does occur at frozen temperatures thought to characterize comets stored in the Oort cloud $[19,20]$.

Another important example is methanol. Methanol $\left(\mathrm{CH}_{3} \mathrm{OH}\right)$ is the simplest organic alcohol; it is an important precursor of more complex pre-biotic species and its presence in several astrophysical environments has been reported [21]. The methanol was irradiated by four different ions beams: $16 \mathrm{MeV}{ }^{16} \mathrm{O}^{5+}, 220 \mathrm{MeV}{ }^{16} \mathrm{O}^{7+}, 600 \mathrm{MeV}$ ${ }^{65} \mathrm{Zn}^{26+}$, and $770 \mathrm{MeV}{ }^{86} \mathrm{Kr}^{31+}$ ions (i.e., $v^{2} \sim 1, \sim 44$, $\sim 14$, and $\sim 10 \mathrm{MeV} / \mathrm{u}$ ions, respectively). The FTIR spectrum obtained from a pure $\mathrm{CH}_{3} \mathrm{OH}$ sample was similar to previous studies [22]. 


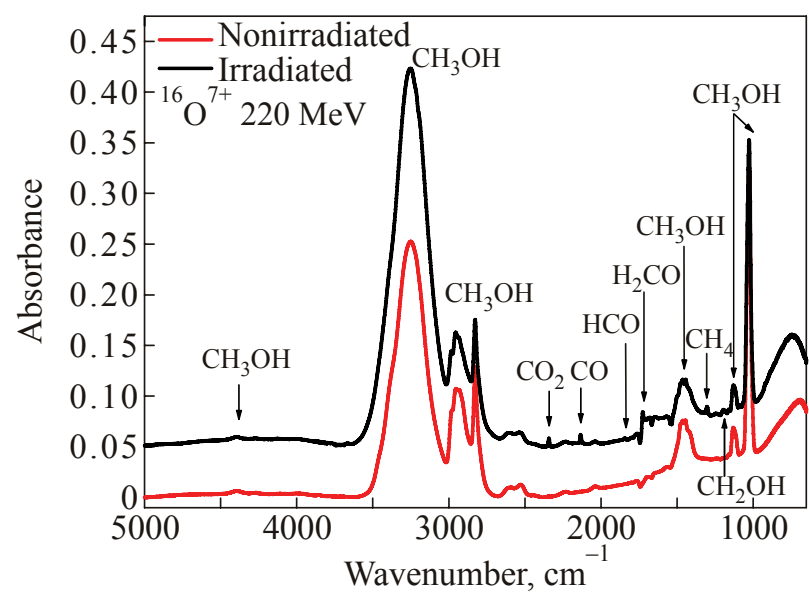

Fig. 4. Comparison of the infrared spectra of the methanol ice at $15 \mathrm{~K}$, before irradiation (lower line) and after irradiation fluence of $2 \cdot 10^{13}$ ions $/ \mathrm{cm}^{2}$ for $220 \mathrm{MeV}^{16} \mathrm{O}^{7+}$ ion beam [27].

Segments of typical spectra are shown in Fig. 4, for oxygen ion beam. The $800-5000 \mathrm{~cm}^{-1}$ range of infrared spectra of the methanol ice at $15 \mathrm{~K}$ are shown, before irradiation (lower) and after irradiation (upper). The $\mathrm{CO}_{2}$ band appears at $2342 \mathrm{~cm}^{-1}$, and $\mathrm{C}_{3} \mathrm{O}_{2}$ occurs in two bands: $v_{1}$ at $2193 \mathrm{~cm}^{-1}$ and $v_{3}$ at $2233 \mathrm{~cm}^{-1}$ [23]. The band at $2233 \mathrm{~cm}^{-1}[24,25]$ is attributed to $\mathrm{H}_{2} \mathrm{O}$ before irradiation. The $\mathrm{CO}$ band appears at $2136 \mathrm{~cm}^{-1}$. The formation of $\mathrm{H}_{2} \mathrm{CO}$ at $1720 \mathrm{~cm}^{-1}$ [22-26] is also observed. Finally, the peaks $\mathrm{CH}_{4}$ at $1304 \mathrm{~cm}^{-1}$, and $\mathrm{C}_{2} \mathrm{H}_{4}(\mathrm{OH})_{2}$ (ethylene glycol) at $1090 \mathrm{~cm}^{-1}$ [26] are visible. In addition, a weak band is visible near $1160 \mathrm{~cm}^{-1}$ which we attribute to $\mathrm{CH}_{3} \mathrm{OCHO}$.

\section{2. $\mathrm{CO}$ and $\mathrm{CO}_{2}$ experiments}

The extremes of chemical oxidation for carbon are represented by hydrocarbons (reduced carbon) and carbon oxides. Having commented on hydrocarbon radiation chemistry, the radiation effects on the important ices $\mathrm{CO}$ and $\mathrm{CO}_{2}$ are discussed.

Our investigation extends towards lower energy the analysis of the interaction of solar wind constituents with carbon monoxide ices present on the comet surfaces of the Oort cloud. This interaction is studied by bombarding a thin layer of $\mathrm{CO}$ with $28 \mathrm{keV}^{16} \mathrm{O}^{6+}$ ions [9], an energy that is slightly above to that of the maximum abundance of solar wind distribution, as shown in Fig. 5. Before irradiation, the only molecular species present in the sample was carbon monoxide. Six optical absorptions were then identified: the fundamental stretching peak $\left(v_{1}\right)$ centered at $2136 \mathrm{~cm}^{-1}$, the fundamental plus lattice vibration combination band $\left(v_{1}+v_{L}\right), 2208 \mathrm{~cm}^{-1}$ peak, the first overtone of the fundamental $\left(2 v_{1}\right)$ at $4251 \mathrm{~cm}^{-1}$, the ${ }^{13} \mathrm{C}$ peak of the $\mathrm{CO}$ fundamental $\left(v_{1}\right)$ at $2091 \mathrm{~cm}^{-1}$, and the $\mathrm{C}^{18} \mathrm{O}$ peak at $2088 \mathrm{~cm}^{-1}$. One additional peak lies at $2112 \mathrm{~cm}^{-1}$, which results from the vibrations of carbon monoxide molecules that are chemisorbed to the substrate. The $\mathrm{C}-\mathrm{O}$ bond is

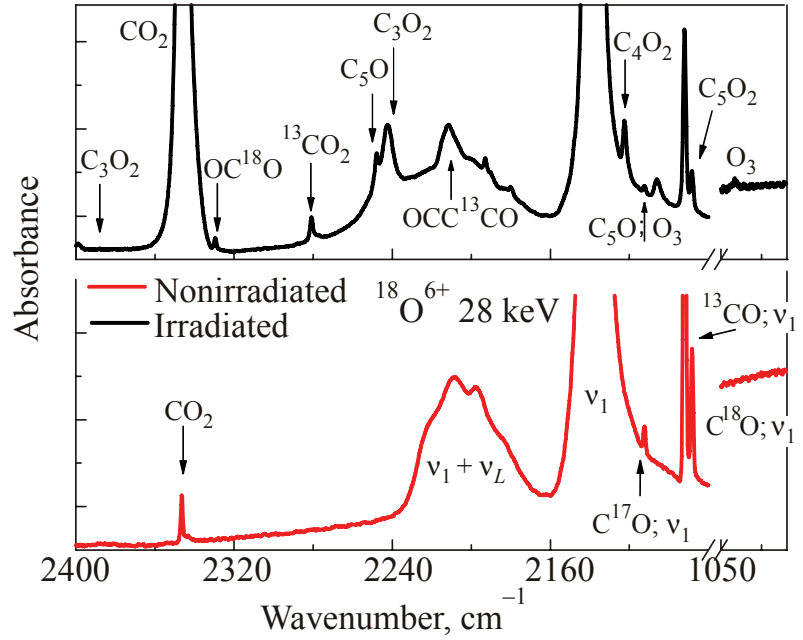

Fig. 5. Infrared spectrum of $\mathrm{CO}$ ice before and after $28 \mathrm{keV}$ ${ }^{18} \mathrm{O}^{6+}$ irradiation [9] with a fluence of $1.17 \cdot 10^{13}$ ions $/ \mathrm{cm}^{2}$.

weakened due to the antibonding $2 \pi * \mathrm{CO}$ orbital resulting in weaker energy of vibration [9].

$\mathrm{CO}$ ices were also irradiated with $\mathrm{Ni}$ ions at high energy - 52 and $537 \mathrm{MeV}$. These results simulate the effects produced by high-energy heavy cosmic-ray ions in interstellar grain mantles $[23,28]$. The $\mathrm{CO}$ radiolysis effects induced by nickel ions, protons $(200 \mathrm{keV}[29,30] ; 800 \mathrm{keV}$ [24]); photons (10.2 eV [24,29,31,32]), and electrons (5 keV [33]) are quite similar.

\subsection{Mixtures}

A study on the interaction of heavier and energetic ions (46 $\mathrm{MeV}^{58} \mathrm{Ni}^{13+}$ ) with ammonia-containing ices $\mathrm{H}_{2} \mathrm{O}: \mathrm{NH}_{3}$ (1:0.5), $\mathrm{H}_{2} \mathrm{O}: \mathrm{NH}_{3}: \mathrm{CO}(1: 0.6: 0.4)[8]$ and $\left(220 \mathrm{MeV}^{16} \mathrm{O}^{7+}\right)$ with $\mathrm{H}_{2} \mathrm{O}: \mathrm{H}_{2} \mathrm{CO}(10: 9$, this ice also contained $5 \%$ of $\mathrm{CH}_{3} \mathrm{OH}$ ), were performed to simulate physical chemistry effects induced by heavy-ion cosmic rays inside dense astrophysical environments.

Mixtures of $\mathrm{NH}_{3}$ and $\mathrm{CO}$ with water seem to have a similar dissociation rate [8], reaching half the initial values at a fluence of about $10^{12}$ ions $/ \mathrm{cm}^{2}$. It was observed that the column density of water decreases too slowly as the fluence increases. This is attributed to a persistent deposition of water from the residual gas. This effect was not observed in previous experiments for pure $\mathrm{CO}$ and $\mathrm{CO}_{2}$ ices $[7,23]$, being probably related to the deposition of water-containing ices; however, it was also observed in the mixture with $\mathrm{H}_{2} \mathrm{CO}$.

A recent and nonpublished experiment of the mixture $\mathrm{H}_{2} \mathrm{O}: \mathrm{H}_{2} \mathrm{CO}$ irradiated with $220 \mathrm{MeV}{ }^{16} \mathrm{O}^{7+}$ ions (i.e., $v^{2} \sim 14 \mathrm{MeV} / \mathrm{u}$ ions at $15 \mathrm{~K}$ ) is presented in Fig. 6. Several absorption bands due to molecular vibrations of $\mathrm{H}_{2} \mathrm{CO}: \mathrm{H}_{2} \mathrm{O}$ before and after irradiation, are observed in the spectra of this figure. In Fig. 6, a, two entire infrared spectra of the $\mathrm{H}_{2} \mathrm{CO}: \mathrm{H}_{2} \mathrm{O}$ ice are shown: before irradiation (lower spectra) and after irradiation (upper spectra). For 

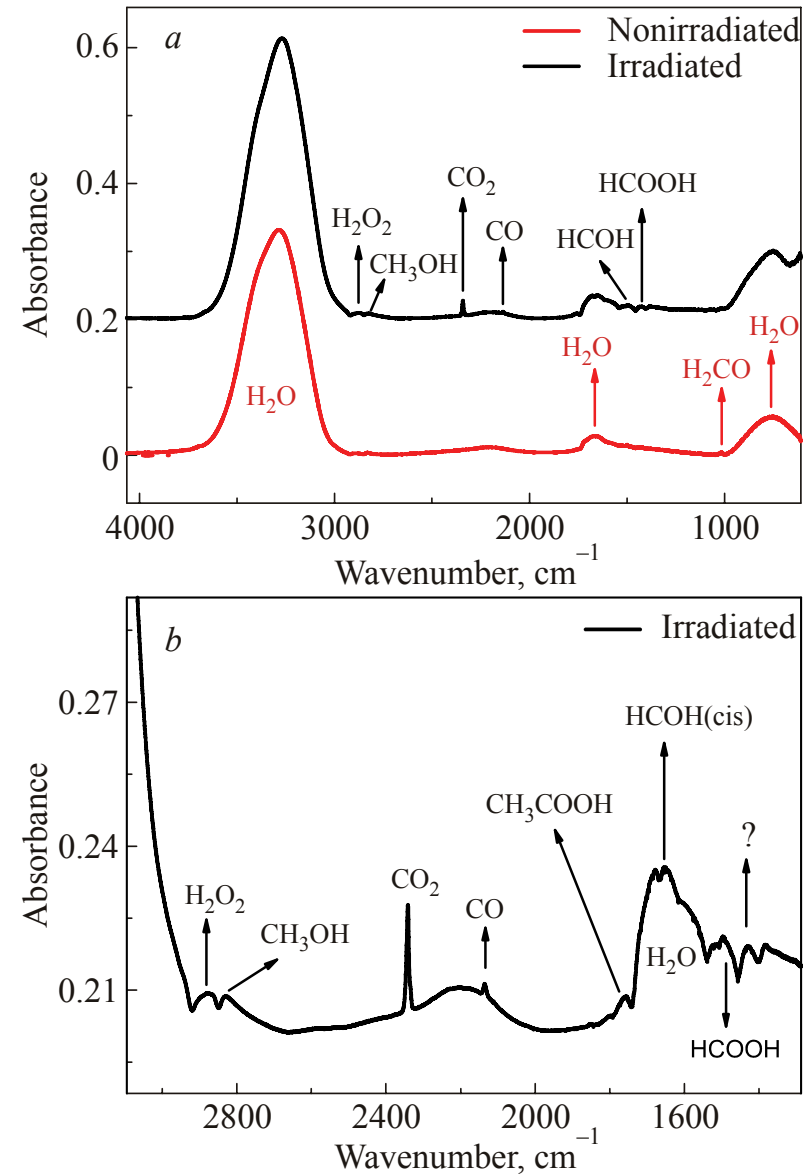

Fig. 6. (a) Comparison of the infrared spectra of the $\mathrm{H}_{2} \mathrm{O}: \mathrm{H}_{2} \mathrm{CO}$ ice at $15 \mathrm{~K}$, before (botton) and after irradiation with fluence of $2.1 \cdot 10^{13}$ ions $/ \mathrm{cm}^{2}$ by $220 \mathrm{MeV}{ }^{16} \mathrm{O}^{7+}$ ion beam (upper line). (b) A zoom of the irradiated sample spectrum at region 3100 to $1300 \mathrm{~cm}^{-1}$.

water we observed three predominant bands: $3250 \mathrm{~cm}^{-1}$, $1651 \mathrm{~cm}^{-1}$ and $760 \mathrm{~cm}^{-1}$. Formaldehyde, $\mathrm{H}_{2} \mathrm{CO}$, could be identified via its fundamental $1249 \mathrm{~cm}^{-1}$ band, which is relatively isolated and has been used previously to constrain $\mathrm{H}_{2} \mathrm{CO}$ production [22]. These bands were also identified by Gerakines et al. [31] as well as by Hudson \& Moore [26]. In Fig. 6, $b$ an expanded segment of the irradiated sample spectrum is presented. The $\mathrm{CO}_{2}$ band is seen at $2342 \mathrm{~cm}^{-1}$ while $\mathrm{CO}$ band appears at $2138 \mathrm{~cm}^{-1}$. In addition, an unknown weak band appears near $1384 \mathrm{~cm}^{-1}$. The $2850 \mathrm{~cm}^{-1}$ band is attributed to $\mathrm{H}_{2} \mathrm{O}_{2}$ [34]. For methanol ice we notice a $v_{3}$ band at $2827 \mathrm{~cm}^{-1}$ [27]; HCOH identified by the $v_{4}-1430 \mathrm{~cm}^{-1}$ band [22]. The band at $1738 \mathrm{~cm}^{-1}$ is due to the $\mathrm{CHOH} v_{14}=\mathrm{HCOH}$ (cis); HCO at $1853 \mathrm{~cm}^{-1}$ band [35] and a small peak around $1762 \mathrm{~cm}^{-1}$ that can be due to $\mathrm{CH}_{3} \mathrm{COOH}$ [36] or $\mathrm{HCOCH}_{2} \mathrm{OH}$ [22]. The very small bands at $1072 \mathrm{~cm}^{-1}$ are attributed to HCOOH molecules [35].

The study of column density variation of synthesized molecules in $\mathrm{H}_{2} \mathrm{O}: \mathrm{H}_{2} \mathrm{CO}$ mixtures shows that $\mathrm{HCOOH}$ is a small product of oxygen beam irradiation. We also observed that the destruction yield of $\mathrm{H}_{2} \mathrm{CO}$ is much higher than that found by Moore et al. [37]. One possible explanation is the fact that, in their mixture, the concentration of $\mathrm{H}_{2} \mathrm{O}$ was five times higher than $\mathrm{H}_{2} \mathrm{CO}$, and furthermore in our case very energetic ion beams were employed. Other molecular species such as $\mathrm{CO}, \mathrm{CH}_{3} \mathrm{OH}, \mathrm{HCOOH}$ and the $\mathrm{HCO}$ it is possible to observe an interesting point: the abundance of all the species finished at the same value as with proton irradiation, except for $\mathrm{CH}_{3} \mathrm{OH}$ that is one of the most abundant species that where destroyed with $220 \mathrm{MeV}$ oxygen ions.

\section{Destruction cross section}

Initially, the sample is formed only by precursor molecules. As irradiation goes on, they may either be destroyed (dissociation) or be ejected (sputtering) by the projectile ions. The column density evolves with an exponential behavior, as can be seen for example in Fig. 7, for the case of $\mathrm{CH}_{3} \mathrm{OH}$. In the methanol experiment, seven $\mathrm{CH}_{3} \mathrm{OH}$ optical absorptions bands were identified. Methanol can be observed by the infrared spectroscopy via many different transitions, such as: (i) a small band at $4393 \mathrm{~cm}^{-1}$ due to the $\mathrm{OH}$ stretching mode; (ii) a intense band centered at $3250 \mathrm{~cm}^{-1} \mathrm{OH}$ due to a stretching mode (mixture with the water band); (iii) two weak bands at 2959 or $2627 \mathrm{~cm}^{-1}$ due to the combination mode of the $\mathrm{CH}$ stretch symmetric and asymmetric stretch mode, respectively; (iv) a $1457 \mathrm{~cm}^{-1}$ band due to $\mathrm{CH}_{3}$ deformation modes; (v) a weak band at $1129 \mathrm{~cm}^{-1}$ is due to the $\mathrm{CH}_{2}$ or $\mathrm{CH}_{3}$ rock; and (vi) a very intense band at $1026 \mathrm{~cm}^{-1}$ is due to $\mathrm{CO}$ stretching mode [27].

The effects of ion irradiation on pure $\mathrm{CH}_{3} \mathrm{OH}$ as a function of the column density and beam projectile fluence, for the $16 \mathrm{MeV}^{16} \mathrm{O}^{5+}, 220 \mathrm{MeV}{ }^{16} \mathrm{O}^{7+}, 600 \mathrm{MeV}^{65} \mathrm{Zn}^{26+}$ and $770 \mathrm{MeV}^{86} \mathrm{Kr}^{31+}$ are shown in Fig. 8 .

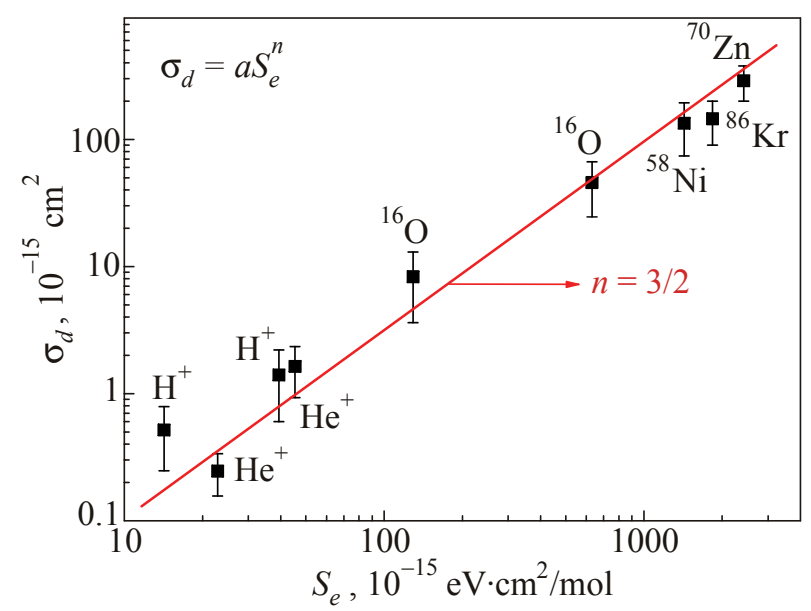

Fig. 7. The dependence of $\mathrm{CH}_{3} \mathrm{OH}$ destruction cross section on the electronic stopping power. Data for 16 and $220 \mathrm{MeV} \mathrm{O,} \mathrm{Zn,}$ and $\mathrm{Kr}$ are results of the de Barros et al. [27]. For lower energy beam see $[25,41,42]$. The lines correspond to the function $\sigma_{d} \sim S_{e}^{n}$, for $3 / 2$ (solid line). 


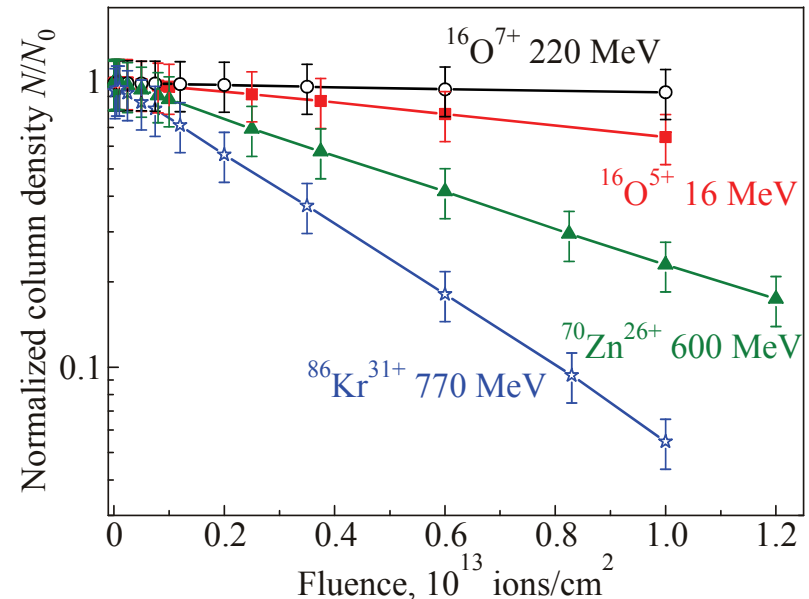

Fig. 8. Ion irradiation on pure $\mathrm{CH}_{3} \mathrm{OH}$ as a function of the column density and beam projectile fluence, for the $16 \mathrm{MeV}{ }^{16} \mathrm{O}^{5+}$, $220 \mathrm{MeV}^{16} \mathrm{O}^{7+}, 600 \mathrm{MeV}^{65} \mathrm{Zn}^{26+}$ and $770 \mathrm{MeV}^{86} \mathrm{Kr}^{31+}$.

The determination of the destruction cross section $\sigma_{d}$ of the precursor molecules can be obtained by a simple model. $L_{1}$ and $Y_{1}$ are defined as the layering and the sputtering yields, respectively; $\Omega_{1}(F)$ is the coverage of the precursor species (1) on the sample surface after the beam fluence $F . N_{j}$ is the column density of molecular species $\mathrm{i} ; \sigma_{f}$ and $\sigma_{d}$ are their formation and destruction cross sections, respectively. Data evolution can be described by the system of differential equations [23]:

$$
\frac{d N_{1}}{d F}=\sum_{j} \sigma_{f, 1 j} N_{j}+L_{1}-\sigma_{d, i} N_{1}-Y_{1}(0) \Omega_{1}(F) .
$$

If no layering occurs during the irradiation and if no recombination takes place (i.e., the precursor molecule is not formed from its own fragments), then $L_{1}=0$ and $\sigma_{f, 1 j}=$ $=0$. Moreover, since $\Omega_{1}(F)$ is proportional to $N_{1}(F)$, the solution of Eq. (5) is

$$
N_{1}(F)=N_{1,0} \exp \left[-F\left(\sigma_{d, 1}+\frac{Y_{1}(0)}{N_{1,0}}\right)\right] .
$$

Fitting the experimental data with this expression, the values of $N_{1,0}$ and of the sum $\sigma_{d, 1}+Y_{1}(0) / N_{1,0}$ are determined, but not the $\sigma_{d, 1}$ and $Y_{1}(0)$ values individually.

The occurrence of the layering (intentionally or not) of a gas distinct from the sample stops the sputtering (i.e., $\left.Y_{1}(F)=Y_{1}(0)=0\right)$, which allows the $\sigma_{d}$ determination unambiguously.

Table 1 lists the ices studied to date. In each case, their molecules were irradiated in $\mathrm{H}_{2} \mathrm{O}$ ice, usually at a concen-

\begin{tabular}{|c|c|c|c|c|}
\hline Molecule & ( Mixture $\mathrm{H}_{2} \mathrm{O}: \mathrm{NH}_{3}: \mathrm{CO}: \mathrm{H}_{2} \mathrm{CO}: \mathrm{CO}_{2}$ & Projectile / Energy & $\sigma_{d}, 10^{-13} \mathrm{~cm}^{2}$ & Reference \\
\hline $\mathrm{CO}$ & $\begin{array}{c}\text { pure } \\
\text { pure } \\
\text { pure } \\
(1: 0.6: 0.4: 0: 0) \\
(1: 0.6: 0.4: 0: 0) \\
(1: 0.6: 0.4: 0: 0) \\
\end{array}$ & $\begin{array}{c}52 \mathrm{MeV} \mathrm{Ni}^{13+} \\
537 \mathrm{MeV} \mathrm{Ni}^{24+} \\
28 \mathrm{keV}^{16} \mathrm{O}^{6+} \\
46 \mathrm{MeV} \mathrm{Ni}^{1+} \\
46 \mathrm{MeV} \mathrm{Ni}^{1+} \\
46 \mathrm{MeV} \mathrm{Ni}^{1+} \\
\end{array}$ & $\begin{array}{c}1 \\
0.3 \\
0.2 \\
1.9 \\
1.9 \\
1.9\end{array}$ & $\begin{array}{c}{[23] \text { and [28] }} \\
\text { [23] and [28] } \\
{[9]} \\
{[8]} \\
{[8]} \\
{[8]}\end{array}$ \\
\hline $\mathrm{CO}_{2}$ & $\begin{array}{c}\text { pure } \\
\text { pure } \\
(1: 0: 0: 0: 1) \\
(10: 0: 0: 0: 1) \\
(0: 0: 0: 0: 1) \\
\end{array}$ & $\begin{array}{l}46 \mathrm{MeV} \mathrm{Ni}^{11+} \\
52 \mathrm{MeV} \mathrm{Ni}^{13+} \\
52 \mathrm{MeV} \mathrm{Ni}^{13+} \\
52 \mathrm{MeV} \mathrm{Ni}^{13+} \\
28 \mathrm{keV}^{16} \mathrm{O}^{6+} \\
\end{array}$ & $\begin{array}{l}1.7 \\
1.8 \\
1.6 \\
\sim 1 \\
0.2 \\
\end{array}$ & $\begin{array}{c}23] \text { and [28] } \\
{[38]} \\
{[38]} \\
{[38]} \\
{[9]} \\
\end{array}$ \\
\hline $\mathrm{CH}_{4}$ & pure & $220 \mathrm{MeV} \mathrm{O}^{7+}$ & $\sim 0.04$ & {$[18]$} \\
\hline $\mathrm{H}_{2} \mathrm{O}$ & $\begin{array}{c}(1: 0: 1: 0: 0) \\
(1: 0.5: 0: 0) \\
\text { pure } \\
(10: 0: 0: 0: 1) \\
(1: 0: 0: 0: 1) \\
(1: 0: 0: 1: 0) \\
\end{array}$ & $\begin{array}{l}46 \mathrm{MeV} \mathrm{Ni}^{11+} \\
46 \mathrm{MeV} \mathrm{Ni}^{11+} \\
52 \mathrm{MeV} \mathrm{Ni}^{13+} \\
52 \mathrm{MeV} \mathrm{Ni}^{13+} \\
52 \mathrm{MeV} \mathrm{Ni}^{13+} \\
220 \mathrm{MeV} \mathrm{O}^{7+}\end{array}$ & $\begin{array}{c}\sim 2 \\
\sim 2 \\
1.1 \\
\sim 1 \\
\sim 10 \\
0.2 \\
\end{array}$ & $\begin{array}{l}{[8]} \\
{[8]} \\
{[8]} \\
{[8]} \\
{[8]} \\
{[39]}\end{array}$ \\
\hline $\mathrm{H}_{2} \mathrm{CO}$ & $(1: 0: 0: 1: 0)$ & $220 \mathrm{MeV} \mathrm{O}^{7+}$ & 0.2 & [39] \\
\hline $\mathrm{NH}_{3}$ & $\begin{array}{c}(1: 0.5: 0: 0: 0) \\
(1: 0.6: 0.4: 0: 0)\end{array}$ & $\begin{array}{l}46 \mathrm{MeV} \mathrm{Ni}^{11+} \\
46 \mathrm{MeV} \mathrm{Ni}^{11+}\end{array}$ & $\begin{array}{l}1.3 \\
1.4 \\
\end{array}$ & $\begin{array}{l}{[8]} \\
{[8]} \\
\end{array}$ \\
\hline $\mathrm{HCOOH}$ & pure & $267 \mathrm{MeV} \mathrm{Fe}^{22+}$ & 1.4 & {$[40]$} \\
\hline $\mathrm{CH}_{3} \mathrm{OH}$ & $\begin{array}{l}\text { pure } \\
\text { pure } \\
\text { pure } \\
\text { pure }\end{array}$ & $\begin{array}{c}220 \mathrm{MeV} \mathrm{O}^{7+} \\
16 \mathrm{MeV} \mathrm{O}^{5+} \\
606 \mathrm{MeV} \mathrm{Zn}^{26+} \\
774 \mathrm{MeV} \mathrm{Kr}^{31^{+}}\end{array}$ & $\begin{aligned} & 0.2 \\
\sim & 0.5 \\
\sim & 1.4 \\
\sim & 2.9\end{aligned}$ & $\begin{array}{l}{[27]} \\
{[27]} \\
{[27]} \\
{[27]}\end{array}$ \\
\hline
\end{tabular}

Table 1. Destruction cross sections for molecules at $\sim 14 \mathrm{~K}$, identified in related experiment 
tration of $20 \%$ or less. IR spectra were taken and product identifications were made. The results of these experiments reveal the main products of radiation processing in each case and allow us to determine radiation lifetimes for various molecules.

\section{Discussion and conclusions}

The present experiments on radiation chemical effects led to a general observation that the destruction cross sections of heavy ions are ruled by a power law as a function of the electronic stopping power: $\sigma_{d} \sim S_{e}^{n}$. We show as example $\mathrm{CH}_{3} \mathrm{OH}$ ice, for which literature data were included in the analysis (Fig. 8). For $\mathrm{CH}_{3} \mathrm{OH}$ the $n$ value was $\sim 3 / 2$. The main conclusion is that molecular destruction by fast ions is an over-linear phenomenon as a function of the transferred energy. High stopping power interactions are more efficient to dissociate the matrix molecules and also, as a consequence, to produce new chemical species. The same average value $n \sim 3 / 2$, was observed as well as in experiments with pure $\mathrm{HCOOH}$ [40], pure $\mathrm{CH}_{4}$ ices [18], and in the mixture $\mathrm{H}_{2} \mathrm{O}: \mathrm{H}_{2} \mathrm{CO}$ for the $\mathrm{H}_{2} \mathrm{CO}$ molecule [39]. Measurements using other matrixes are being performed in order to verify if this law can be generalized.

Another interesting effect is that heavy ion radiation processing is very efficient in producing certain molecular species in ices. These species include $\mathrm{CO}, \mathrm{CO}_{2}, \mathrm{CH}_{4}$, $\mathrm{CH}_{3} \mathrm{OH}$, and $\mathrm{HCOOH}$. Each of these can be produced in sufficient yield from suitable laboratory precursors to account for observed abundances in many astronomical ices. A challenge for experimentalists is to determine the conditions under which the formation of such molecules might either be enhanced or hindered. In contrast to these "favored" molecules, we have found difficulties to detect other types. This occur in particular for molecules that are not seen by FTIR. These molecules may form part of the residual material already described, but such samples are not easily analyzed by conventional IR spectroscopy.

A useful concept in this kind of analysis is thermodynamic stability. Ionizing radiation drives the ice toward a more stable composition, reactants to products. However, if the experiment is repeated starting with the products, the original reactants are recovered as the ice approaches an equilibrium composition. Many examples can be given. Irradiation of $\mathrm{CO}$ in amorphous $\mathrm{H}_{2} \mathrm{O}$ ice generates $\mathrm{CO}_{2}$, $\mathrm{CH}_{3} \mathrm{OH}$, and the other products already described. However, irradiation of either $\mathrm{H}_{2} \mathrm{O}: \mathrm{CO}_{2}$ or $\mathrm{H}_{2} \mathrm{O}: \mathrm{CH}_{3} \mathrm{OH}$ ices generates $\mathrm{CO}$. Some other pairs of reactants and products showing this behavior, all in $\mathrm{H}_{2} \mathrm{O}$ matrix ices, are $\mathrm{CO}_{2}$, $\mathrm{H}_{2} \mathrm{CO}_{3}, \mathrm{CH}_{4}, \mathrm{C}_{2} \mathrm{H}_{6}, \mathrm{CH}_{4}, \mathrm{CH}_{3} \mathrm{OH}, \mathrm{H}_{2} \mathrm{CO}, \mathrm{CH}_{3} \mathrm{OH}$ and $\mathrm{CO}, \mathrm{H}_{2} \mathrm{CO}$. This implies in multicomponent ices, such as $\mathrm{H}_{2} \mathrm{O}: \mathrm{NH}_{3}: \mathrm{CO}$ and $\mathrm{H}_{2} \mathrm{O}: \mathrm{H}_{2} \mathrm{CO}$, that complex organic are formed by radiolysis in low yields. Conversely, it also implies that organic molecules, such as amino acids or organic polymers, are destroyed in $\mathrm{H}_{2} \mathrm{O}$ ice by radiation, form- ing $\mathrm{CO}_{2}, \mathrm{NH}_{3}$, and other simple products. Turning from radiation products to radiation processes, it is observed that certain chemical reactions occur in a variety of molecules in $\mathrm{H}_{2} \mathrm{O}$-dominated ices. Double and triple bonds of types $\mathrm{C}=\mathrm{C}, \mathrm{C} \equiv \mathrm{C}, \mathrm{C}=\mathrm{O}$, and $\mathrm{C} \equiv \mathrm{O}$ are converted to single bonds by irradiation in $\mathrm{H}_{2} \mathrm{O}$ ice [43]. Radical-radical reactions to make molecules like $\mathrm{H}_{2} \mathrm{O}_{2}, \mathrm{C}_{2} \mathrm{H}_{6}, \mathrm{CH}_{3} \mathrm{OH}$, and ethylene glycol [44] readily occur and are so common that they can be relied on in ices not yet studied. Nevertheless, the results obtained have shown that one key to understand complex ice chemistry is to start studying simple systems. Certainly there is a need to investigate and understand simple laboratory ices for comparisons to solar system and interstellar ices.

Once the behavior of individual molecules in the pure state is understood, one can turn to a radiation of a mixture for a reasonable set of chemical reactions and products. The situation that has existed up until now, in which each astronomical ice analogue studied represented a single chemical system, is changing as a comprehensive picture of energetic processing emerges.

\section{Acknowledgments}

This work was supported by the region of "BasseNormandie" (France) and by the French-Brazilian exchange program CAPES-COFECUB. It is a pleasure to thank all the collaborators: E. Dartois, E. Seperuelo Duarte, S. Pilling, D. Andrade, V. Bordalo and also Th. Been and J.M. Ramillon, for technical support. The experiment was performed at the GANIL facility in Caen, France. The Brazilian agencies CNPq (INEspaço) and FAPERJ also provided partial support.

1. R. Smith, K. Sellgren, and A. Tokunaga, Astrophys. J. 344, 413 (1989).

2. D. Whittet, A. Adamson, W. Duley, T. Geballe, and A. McFadzen, Mon. Not. R. Astron. Soc. 241, 707 (1989).

3. D. Whittet, R. Smith, A. Adamson, D. Aitken, J. Chiar, T. Kerr, P. Roche, C. Smith, and C. Wright, Astrophys. J. 458, 363 (1996).

4. A. Tielens, A. Tokunaga, T. Geballe, and F. Baas, Astrophys. J. 381, 181 (1991).

5. J. Chiar, A. Tielens, D. Whittet, W. Schutte, A. Boogert, D. Lutz, E. Dishoeck, and M. Berstein, Astrophys. J. 537, 749 (2000).

6. L. D'Hendecourt, L. Allamandola, R. Grim, and J. Greenberg, Astron. Astrophys. 158, 119 (1986).

7. E. Seperuelo Duarte, P. Boduch, H. Rothard, T. Been, E. Dartois, L.S. Farenzena, and E.F. da Silveira, Astron. Astrophys. 502, 599 (2009).

8. S. Pilling, E. Seperuelo Duarte, E.F. da Silveira, E. Balanzat, H. Rothard, A. Domaracka, and P. Boduch, Astron. Astrophys. 509, A87 (2010). 
9. A.L.F. de Barros, A. Domaracka, E. Seperuelo Duarte, P. Boduch, H. Rothard, and E.F. da Silveira, Nucl. Instrum. Meth. Phys. Res. B269, 852 (2011).

10. J. Lannon, F.D. Verderame, and R.W. Anderson, Jr., J. Chem. Phys. 54, 2212 (1971).

11. M. Kernbaum, Le Radium 7, 242 (1919).

12. M. Moore and R.L. Hudson, Icarus 154, 282 (2000).

13. P. Boduch, E.F. da Silveira, A. Domaracka, O. Gomis, X. Lv, M. Palumbo, S. Pilling, H. Rothard, E. Seperuelo Duarte, and G. Strazzulla, Adv. Astron. 2011, Article ID 327641 (2011).

14. R. Carlson, R. Johson, and M. Anderson, Science 286, 97 (1999).

15. R. Kaiser and K. Roessler, Astrophys. J. 474, 144 (1997).

16. G. Foti, L. Calcagno, K. Sheng, and G. Strazzulla, Nature 310, 126 (1984).

17. M. Mumma, M.A. DiSanti, N.D. Russo, M. Fomenkova, K. Magee-Sauer, C.D. Kaminski, and D.X. Xie, Science 272, 1310 (1996).

18. A.L.F. de Barros, V. Bordalo, E. Seperuelo Duarte, E.F. da Silveira, A. Domaracka, H. Rothard, and P. Boduch, Astron. Astrophys. 531, 15 (2011).

19. R. Hudson and M.H. Moore, Icarus 126, 233 (1997).

20. M. Moore and R.L. Hudson, Icarus 135, 518 (1998).

21. K. Willacy and T. Millar, Mon. Not. R. Astron. Soc. 298, 562 (1998).

22. C. Bennett, S.-H. Chen, B.-J. Sun, A. Chang, and R. Kaiser, Astrophys. J. 660, 1588 (2007).

23. E. Seperuelo Duarte, A. Domaracka, P. Boduch, H. Rothard, E. Dartois, and E.F. da Silveira, Astron. Astrophys. 512, A71 (2010).

24. P. Gerakines and M. Moore, Icarus 154, 372 (2001).

25. P. Gerakines, M. Moore, and R. Hudson, J. Geophys. Res. 106, 33381 (2001).

26. R. Hudson and M.H. Moore, Icarus 145, 661 (2000).
27. A.L.F. de Barros, A. Domaracka, D.P.P. Andrade, P. Boduch, H. Rothard, and E.F. da Silveira, Mon. Not. R. Astron. Soc. 418, 1363 (2011).

28. A. Domaracka, E. Seperuelo Duarte, P. Boduch, H. Rothard, J. Ramillon, S. Pilling, L.S. Farenzena, and E.F. da Silveira, Nucl. Instrum. Meth. Phys. Res. B268, 2960 (2010).

29. M. Loeffler, G.A. Barata, M. Palumbo, G. Strazulla, and R. Baragiola, Astron. Astrophys. 435, 587 (2005).

30. M. Palumbo, G. Baratta, D. Fulvio, M. Garozzo, O. Gomis, G. Leto, F. Spinella, and G. Strazzulla, J. Phys. Conf. Series 101, 01200 (2008).

31. P. Gerakines, W. Schutte, and P. Ehrenfreund, Astron. Astrophys. 312, 289 (1996).

32. H. Cottin, M. Moore, and Y. Benilan, Astrophys. J. 590, 874 (2003).

33. C. Jamieson, C. Bennett, A.M. Mebel, and R.I. Kaiser, Astrophys. J. 624, 436 (2005).

34. M. Loeffler, U. Raut, R. Vidal, R. Baragiola, and R. Carlson, Icarus 180, 265 (2006).

35. R. Hudson and M.H. Moore, Icarus 140, 451 (1999).

36. S. Bisschop, J. Jorgensen, T. Bourke, S. Bottinelli, and E. van Dishoeck, Astron. Astrophys. 488, 956 (2008).

37. M. Moore, R. Ferrante, R.L. Hudson, and J.N. Stone, Icarus 190, 260 (2007).

38. S. Pilling, E. Seperuelo Duarte, A. Domaracka, H. Rothard, P. Boduch, and E.F. da Silveira, Astron. Astrophys. 523, A77 (2010).

39. A.L.F. de Barros, et al., In preparation.

40. D.P.P. Andrade, et al., In preparation.

41. R. Brunetto, V. Orofino, and G. Strazzulla, Mem. S. A. It. Suppl. 6, 45 (2005).

42. G.A. Baratta, G. Leto, and M.E. Palumbo, Astron. Astrophys. 384, 343 (2002).

43. R. Hudson and M. Moore, J. Geophys. Res. 106, 275 (2001).

44. R. Hudson, M.H. Moore, and P.A. Gerakines, Astrophys. J. 550, 1140 (2000). 